Revista lus et Praxis, Año 18, No 2, 2012, pp. 189 - 218

ISSN 0717 - 2877

Universidad de Talca - Facultad de Ciencias Jurídicas y Sociales

"Una valoración de la posible Autonomía del 'Derecho de los Museos'

en el ordenamiento jurídico portugués"

Abel Laureano

\title{
UNA VALORACIÓN DE LA POSIBLE AUTONOMÍA DEL "DERECHO DE LOS MUSEOS" EN EL ORDENAMIENTO JURÍDICO PORTUGUÉS*
}

\author{
AN ASSESSMENT ON the POSSIBLE aUtONOMY OF "MuSEUM LAW" \\ IN THE PORTUGUESE LEGAL SYSTEM
}

\begin{abstract}
Abel Laureano**
RESUMEN

El desarrollo y la mayor complejidad de la vida moderna, junto con una tecnicidad cada vez mayor de los instrumentos jurídicos de regulación de la sociedad y con otros factores, han provocado un aumento significativo en la cantidad de normas jurídicas, con el problema inherente de su enmarcación en sectores de cara a permitir una mejor comprensión y aplicación de esas normas; el problema clásico de la división del Derecho en ramas logra, por tanto, una renovada actualidad.

Este estudio se centra, en el contexto de ese problema, sobre la cuestión de la posible autonomía de un conjunto específico de reglas que puede nombrarse como "Derecho de los Museos". Con referencia al actual régimen jurídico portugués, y a la distinción entre distintas formas de autonomía, se llega, en función de esas distintas modalidades, a conclusiones también distintas acerca de la autonomía de aquel conjunto de reglas.
\end{abstract}

ABSTRACT

The development and bigger complexity of modern life, together with an increased technicality of legal instruments of Society's regulation and with other factors, have caused a significant increase in the amount of legal rules, with the inherent problem of their storage into sectors, in order to enable a better understanding and application of those rules; the classic problem of Law division in branches sees, thus, a renewed relevance.

This study focuses, in the context of that problem, on the issue of the possible autonomy of a specific set of rules, which can be named as "Museum Law". With reference to Portuguese today's Legal System, and distinguishing between different forms of autonomy, it comes, depending on the different modalities, to different conclusions about the autonomy of that set of rules.

\footnotetext{
*Trabajo recibido el 22 de agosto y aprobado el 25 de septiembre de 2012.

** Profesor de la Universidad de Porto (Portugal); Doctorando en Derecho Internacional Público y Relaciones Internacionales en la Universidad de Santiago de Compostela (España); Mestre em Direito (Integração Europeia) de la Universidade de Coimbra (Portugal); Diploma em Estudos Europeus (D.E.E.) de la Universidade de Lisboa (Portugal); Pós-Graduação em Estudos Europeus de la Universidade de Lisboa (Portugal); Licenciatura en Derecho de la Universidade de Lisboa (Portugal). Correo electrónico: alaureano1@gmail.com.
} 


\section{PALABRAS CLAVE}

Museos, Derecho de los Museos, Ramas del Derecho

KEYWORDS

Museums, Museum Law, Branches of Law

\section{INTRODUCCIÓN}

\subsection{Objetivo y razón de ser de este estudio}

I. El tema central. La evolución de las sociedades desarrolladas ha dado lugar, como uno de los ingredientes de su perfil, a la importancia cada vez más grande del vector cultural, en respuesta a necesidades o deseos emanados de los pueblos y "apropiados" o incluso "empujados y extendidos" por los Gobiernos.

La dimensión cultural se ha cristalizado, del punto de vista social, en la aparición de la categoría de los "bienes culturales", como piezas componentes de una institución socio-jurídica (el "patrimonio cultural"), que ha creado una razonable "tela" normativa que recibió en Portugal la designación de Derecho del Patrimonio Cultural' ${ }^{1}$.

Una de las grandes "herramientas" sociales al "servicio" de los bienes culturales (haciendo parte de su universo) son los museos, que pueden calificarse como instituciones y ser objeto de normas jurídicas específicas, las cuales pueden agruparse bajo la etiqueta de Derecho de los Museos².

Sin embargo, además de la especificidad de las respectivas normas componentes, ¿constituye el Derecho de los Museos un campo jurídico autónomo? ¿Nos enfrentamos, en otras palabras, a una nueva rama del Derecho? Esta es la cuestión a la cual este estudio busca traer respuesta, en el contexto del actual sistema jurídico portugués.

II. La división del Derecho. Es conveniente alinear algunos datos preliminares sobre la temática de la repartición del Derecho en ramas (es decir, en varias zonas normativas ${ }^{3}$ ), lo que contextualizará la buscada respuesta ${ }^{4}$.

\footnotetext{
${ }^{1}$ Por todos, en la doctrina portuguesa, Casalta Nabals, José, Introdução ao Direito do Património Cultural, $2^{\text {a }}$ ed., Almedina, Coimbra, 2010, y la referencia al título de la monografía es suficiente.

2 El Derecho Museal, en otra preferencia terminológica, como VARRICCHIO, Enzo, "Il Diritto Museale, ontogenesi di una disciplina giuridica", Nuova Museologia, giugno 2008, № 18, pp. 2-7, consultado el 10 de septiembre de 2010, en <http://www.nuovamuseologia.org/n18/n18.pdf>.

${ }^{3}$ Una rama del Derecho es por lo tanto un conjunto coherente y autónomo de reglas, adaptado a un sector específico de actividades (AUBERT, Jean-Luc, Introduction au droit et thèmes fondamentaux du droit civil, $10^{a}$ ed., Armand Colin, Paris, 2004, p. 39). En otra formulación, las ramas del Derecho son esferas más o menos homogéneas de la regulación legal que se corresponden con los distintos sectores de la vida social (AÑon, María José, "Las Ramas del Ordenamiento Jurídico", in J. DE LuCAS (ed.), Introducción a la Teoría del Derecho, $3^{\text {a }}$ ed., Tirant Lo Blanch, Valencia, 1997, pp. 171-193, p. 171).
}

${ }^{4}$ Aunque fuera posible no considerar aquí el problema de las ramas del Derecho, creemos que se justifica un enfoque del mismo, como una forma de apoyar a nuestra comprensión de la cuestión espe- 
En realidad, cuando una porción específica de la realidad humana cognoscible alcanza una cierta dimensión, hay una correlativa tendencia a dividirla en porciones más pequeñas (fracciones, parcelas, partes, zonas, áreas, módulos...) para que pueda gestionarse (incluso como objeto de conocimiento) ${ }^{5}$. El Derecho, como conjunto de las normas jurídicas existentes, representa una enorme riqueza, a la cual se aplican plenamente las consideraciones anteriores: la división del total de lo jurídico permite no sólo encontrar las normas, sino también utilizarlas; y esta operación es esencial, ya que las normas existen para ser aplicadas, regulando así la vida de las personas, la existencia, el mantenimiento y desarrollo de la sociedad humana; el Derecho es una realidad eminentemente viva y activa, que se justifica por la finalidad utilitaria de hacer posible la vida de los Humanos: por lo tanto, la conclusión de que es imperativo (y con particular claridad en la actualidad) segmentar el Derecho ${ }^{6}$, para que su misión pueda cumplirse ${ }^{7}$.

\subsection{El Derecho de los Museos en el contexto de los grupos de ramas del Derecho}

I. La dicotomía Derecho Común / Derecho Institucional. Cuando se habla de la división del Derecho en ramas, se consideran, en primer lugar, por lo general, no las grandes ramas, pero las divisiones de nivel inmediatamente inferior al que tiene lugar en una división (rama) capital (es decir, en una división

cífica del lugar del Derecho de los Museos. Ya que la única justificación, para omitir una referencia al problema mencionado, sería la de que es un objeto clásico de estudio, creemos que no debe superar la conveniencia de exponer las razones de nuestro pensamiento.

${ }^{5}$ Este desmonte como una manera de tratar con vastas áreas de la realidad es una tendencia universal (cfr. la Medicina, la Ingeniería y la lista podría extenderse mucho), que no requiere grandes explicaciones generales adicionales).

${ }^{6}$ Por el recorte del Derecho en diversas partes, el objeto seccionado ven a convertirse en conjuntos más o menos amplios de normas jurídicas. Pero las normas jurídicas pueden ser analizadas, aunque desde una perspectiva científica, de más de un prisma. La segmentación conducente a las ramas del Derecho, en particular, no es más que una clasificación de las normas jurídicas; pero, a diferencia de lo que normalmente se piensa y se dice cuando se habla de "tipologías" o "clasificaciones" de normas jurídicas, agrupa las normas de acuerdo a su contenido material, y no según otros criterios (esa es por lo menos la tendencia; y la reserva presente en la palabra "tendencia" tiene por objeto salvaguardar casos, como por ejemplo el de la bipartición del Derecho en Derecho Interno y Derecho Internacional, que no son pertinentes -a nuestro juicio- a un criterio de distinción material: en el ejemplo, el factor diferenciador es el origen de las normas).

${ }^{7}$ El procedimiento de descomposición intelectual del mundo cognoscible es por lo tanto permisible (incluso necesario) y no tiene contraindicaciones. El punto es (cuidado necesario) que la compartimentación no comprometa las necesarias visiones de conjunto. Esta compartimentación sólo caería en artificial y fuera de lugar, por incorrecta, si acaso generase campos estancos donde no existen ni pueden existir, porque entonces ocurriría una distorsión de la realidad jurídica (es decir, cualquier fraccionamiento no debe ser incompatible con la sustancia del Derecho, cambiándola inadecuadamente). 
suprema o superior); para la identificación de ellas es mejor hablar, quizá, de espacios jurídicos superiores o grupos de ramas del Derecho (aunque a veces los juristas hablen, sencillamente, de "rama", para designar a una partición cualquiera del Derecho, independientemente de su talla). Entre las divisiones máximas del Derecho (hechas de acuerdo a diferentes criterios) se encuentra la ancestral bipartición entre Derecho Público y Derecho Privado, además de otras profundamente estudiadas ${ }^{8}$. Por esta razón (y para no alargar el texto), simplemente llamamos a un primer plan en el presente estudio la distinción entre Derecho Común y Derecho Institucional, comenzando con el primer término de esta clasificación.

Para un breve análisis del concepto de Derecho Común, hay que señalar que, aunque abarcando diversas esferas materiales, el Derecho lo hace a través de la utilización de muchas técnicas que son aplicables en general, independiente del sector en cuestión (normas "técnico-jurídicas" comunes); se encuentra así, por ejemplo, la figura de las obligaciones en el Derecho de Familia, en el Derecho de Sucesiones, en el Derecho Mercantil, en el Derecho del Trabajo...

En otras palabras: hay normas, o figuras jurídicas, adecuadas al tratamiento técnico-jurídico del universo de las zonas materiales de la vida humana; tales normas o figuras adoptan un color específico, en función de las particularidades de cada zona, pero son necesarias para la configuración técnico-jurídica de las diferentes zonas; actúan como instrumentos a los que hay que recurrir para la regulación de cada sector material, que a su vez los colora de acuerdo a sus especificidades; es natural, por lo tanto, que se encuentren algunos matices cuando se comparan entre sí, por ejemplo, obligaciones familiares, sucesorias o mercantiles. Sin embargo, más allá de estos matices, la base regulatoria es la misma9 .

Es, pues, lógico buscar autonomizar un cuerpo que contenga ese tipo de normas "generales" o "comunes"; autonomizar, en definitiva, un Derecho Común, al que se contraponen diversos Derechos Materiales o Institucionales caracterizados por el hecho de utilizaren sus figuras e instrumentos, dándoles tonos específicos (pero siendo estas figuras e instrumentos sus elementos técnico-jurídicos de estructuración). Se entiende así por Derecho Común, en esta dicotomía, el conjunto de normas adecuadas al tratamiento técnico-jurídico del universo de las áreas materiales de la vida humana.

Es esencial, para dibujar el segundo polo de esta clasificación (Derecho Institucional), la idea de institución; para eso, podemos ya caracterizarla como la

\footnotetext{
${ }^{8}$ Como es sabido y recordamos, el binomio Derecho Nacional e Internacional (o Internacional Público), así como el binomio Derecho Sustantivo (o Material) y Adjetivo (o Procesal).

${ }^{9}$ Se trata, en el caso que nos ocupa (y repitiéndolo), de la figura técnico-jurídica de la obligación, cuyas características esenciales e indispensables están, a su vez, previstas en un área "general" o "común" del Ordenamiento Jurídico.
} 
condensación de un núcleo delimitado y suficientemente estable de relaciones humanas (por ejemplo, la "institución familiar") o de aspectos de la actividad humana (por ejemplo, la "institución militar")10; queda claro que, en caso de relaciones o actividades sujetas a la disciplina del Derecho (y sólo esas nos interesan aquí), las instituciones se traducen, jurídicamente, en cuerpos normativos delimitados. Para refinar la noción, así algo toscamente dibujada, de institución, cabe señalar que, en Derecho, esta realidad va junta con la figura llamada instituto. Hay incluso a veces una cierta indistinción en el uso de ambos términos. Sin embargo, al menos como tendencia, la idea de institución es más amplia que la de instituto ${ }^{11}$.

Cuando se ve desde una perspectiva factual, el sustrato de estos conceptos se refleja en un conjunto de relaciones humanas caracterizadas por una cierta estabilidad e individualización de cuerpo. Cuando se analiza desde una perspectiva jurídica, se ve, a su vez y en paralelo, una red estable y distinta de relaciones jurídicas; lo mismo es hablar (porque las relaciones sólo se convierten en "jurídicas" cuando regladas por normas de Derecho) de una red estable y distinta de normas jurídicas ${ }^{12}$. Por lo tanto, la noción de familia, por ejemplo (e independientemente de las distintas configuraciones históricas o de civilización), es algo que (de existir jurídicamente) llama a sí misma una disciplina jurídica propia, moldeada sobre las "características de cuerpo" de esa realidad, reconocida como distinta y poseedora de un cierto grado de estabilidad existencial. Se puede decir, en definitiva, que el Derecho Institucional es el conjunto de normas que regulan una institución, si la miramos como un conjunto de relaciones humanas caracterizadas por alguna estabilidad e individualización de cuerpo.

II. El Derecho de los Museos en el marco de la dicotomía Derecho Común / Derecho Institucional. En la dicotomía Derecho Común / Derecho Institucional, el Derecho de los Museos se encuentra claramente en el campo del Derecho Institucional. De hecho, todo él gira en torno a la institución museo, calificativo que, además, le atribuye la "Ley de los Museos"13 (LM), según la cual (un poco

\footnotetext{
${ }^{10}$ En el mismo sentido, por ejemplo, y por todos, Massimo Bianca, C., Diritto civile, Vol. I, La norma giuridica. I soggetti, $2^{a}$ ed., Giuffrè, Milano, 2002, p. 6.

${ }^{11}$ Se habla, por ejemplo, de la institución "familia", mientras se alude a los institutos "matrimonio" (referente a un solo aspecto de la familia, el de su creación) o "filiación" (otro de los aspectos del "cosmos" familiar).

${ }^{12}$ En Portugal, por ejemplo, Gomes conceptualiza la institución jurídica como un subsistema de reglas, agrupadas en torno a una idea central (SÁ Gomes, Nuno, Introdução ao Estudo do Direito, Lex, Lisboa, 2001, p. 30).

${ }^{13}$ Oficialmente nombrada como Ley Marco de los Museos Portugueses ("Lei Quadro dos Museus Portugueses") (Ley No 47/2004, del 19 de agosto).
} 
redundantemente) el museo es "una institución de naturaleza permanente" (artículo $3^{\circ}$, apartado 1, parte inicial de la LM).

El concepto de museo aquí puesto no es, además, una particularidad portuguesa; habrá cosechado inspiración en el Código de Deontología para los Museos, del Consejo Internacional de Museos (ICOM), que define el museo como "una institución permanente, sin fines de lucro y al servicio de la sociedad y su desarrollo, que es accesible al público y acopia, conserva, investiga, difunde y expone el patrimonio material e inmaterial de los pueblos y su entorno para que sea estudiado y eduque y deleite al público"14.

\subsection{Secuencia: formas de autonomía de las ramas del Derecho}

Aceptada a priori la legitimidad de un fraccionamiento (teórico y práctico) del Derecho, debe añadirse que lo que conduce a repartirlo (tomado en su materialidad) en ramas es la necesidad de acudir a tres tipos de preocupaciones: preocupaciones de conocimiento, preocupaciones de transmisión de conocimiento y preocupaciones eminentemente pragmáticas, las cuales se traducen en otros tantos vectores (científicos, didácticos y prácticos) de esta división del Derecho. Puede ocurrir, además, alguna articulación concreta de estas distintas preocupaciones ${ }^{15}$.

Examinaremos a continuación el lugar ocupado, por el Derecho de los Museos, en relación con la temática de las ramas del Derecho. Intentaremos, en este estudio, posicionar el Derecho de los Museos frente a los vectores de la autonomía científica, de la autonomía didáctica y de la autonomía práctica.

\section{El Derecho de los Museos y la autonomía científica}

\subsection{Una aproximación al problema general del marco científico}

I. La segmentación del objeto de la Ciencia del Derecho. Una cualquier área del Derecho tiene autonomía científica cuando esté justificado, de un punto de vista de la Ciencia, tenerla en cuenta a parte de otras áreas. Las áreas del conocimiento científico se definen (o delimitan) por un objeto y un método propios; así ocurre por lo que va de la Ciencia Jurídica o Ciencia del

${ }^{14}$ Consejo Internacional de Museos (ICOM), Código de Deontología del ICOM para los Museos, p. 14, consultado el 6 de julio de 2011, en <http://www.icom-ce.org/contenidos09.php?id=29>.

${ }^{15}$ Sobre la versatilidad, variabilidad y plasticidad de la división del Derecho en ramas, ya se ha dicho que cualquier división es más o menos artificial, al igual que el cuerpo humano, pues el anatomista lo descompone en aparato de cinética, órganos internos, nervios y vasos sanguíneos, pero también se puede descomponer en función del origen embriológico de los órganos o, para otros fines, aun según otros puntos de vista (REHBINDER, Manfred, Einführung in die Rechtswissenschaft: Grundfragen, Grundlagen und Grundgedanken des Rechts, $8^{a}$ ed., De Gruyter, Berlin-New York, 1995, p. 87). 
Derecho (stricto et proprio sensu), cuyo objeto es el Derecho y cuyo método es el método jurídico. Pero, debido a que la Ciencia del Derecho es muy amplia, se subdivide en varias sub-áreas del conocimiento; como el método empleado por ellas es siempre el método jurídico, la diferencia sólo puede estar en el objeto; y así sucede: como el objeto es el Derecho, las ditas subáreas del conocimiento son en última instancia lo que tradicionalmente se llaman ramas del Derecho.

II. El criterio de segmentación (materias autónomas y principios propios). Pero, ¿Cómo se define científicamente una rama del Derecho? ¿Cuál es la base del criterio? Puesto que (insistimos) el método, en el marco jurídico-científico, debe inevitablemente ser el método jurídico, las diferencias residirán necesariamente en el objeto: este es siempre el Derecho, pero pueden verse divisiones en él. Tales divisiones pueden caracterizarse en función de principios propios, a su vez relacionados con (o derivados de) diferencias de materias que constituyen el universo jurídico.

La vida social tiene múltiples facetas: el hombre rompe abajo en múltiples actividades y vive integrado en estructuras complejas; esta pluralidad de la vida social aconseja inmediatamente una correspondiente diversidad de normas de regulación (segmentación primaria por materia). Por otra parte -y completando- la Ciencia del Derecho es una ciencia práctica y su objeto es el mejor encuadramiento del acervo normativo-jurídico, de cara a iluminar su hechura, comprensión, organización y posterior ejecución; así las cosas, los sectores de la Ciencia del Derecho tendrán que definirse por referencia a objetos jurídicos que se distingan no sólo por los hechos objeto de las normas, sino también por algo más: por rasgos jurídicos distintivos; dicho de otra manera: las áreas de la Ciencia Jurídica habrán de referirse a universos de normas aglutinadas por la referencia a una materia separable, esto también en el sentido de tratarse de bloques de materia que reclamen una disciplina sujeta a principios propios ${ }^{16}$. Es mediante la concurrencia de ambos los ingredientes que se cubrirán, así, unidades jurídicas inconfundibles.

Estos dos vectores (materias autónomas y principios propios) sirven como anverso y reverso de una misma moneda (conexión de los vectores del criterio). Básicamente, sólo hay autonomía de materias, para este propósito, si su tratamiento jurídico es diferente de acuerdo con principios de regulación distintos.

\footnotetext{
${ }^{16}$ Sin ningún tipo de referencia a materias, se argumentó que la existencia de una rama del Derecho refleja la autonomía de sus principios y sus conceptos (CABRILAC, Rémy, Introduction générale au droit, $5^{a}$ ed., Dalloz, París, 2003, p. 61). En Portugal, se ha consignado que sólo es rama del Derecho el sector normativo que tenga autonomía científica por haber originado la formulación de principios generales propios que permitan un tratamiento técnico y sistemático peculiar (Gomes, Nuno Sá, cit., p. 229).
} 
Son éstos los que constituyen la columna vertebral de un cuerpo normativo identificable como autónomo ${ }^{17}$.

Podemos decir, sin embargo, que detrás de estas materias jurídicas así autónomas, hay materias sociales demandantes de distintas disciplinas jurídicas (materias jurídicas vs. materias sociales): después de todo, los principios jurídicos que contienen y delimitan las líneas maestras de los conjuntos normativos llamados "ramas del Derecho" no son más que la traducción, en el mundo jurídico, de las específicas necesidades de regulación de cada "zona" de la vida social susceptible de autonomía. Ya puede verse entonces que, cuando hablamos de materia en este contexto, estamos usando la palabra de una manera menos común. La clave, aquí, serán básicamente los principios; después de todo es la existencia, o no, de principios propios, lo que dará lugar a la autonomía, o no, de una rama del Derecho.

Pero ¿qué cantidad o importancia o tipo de principios? Aquí surgen las dudas. Podría intentarse superarlas a través del recurso a la idea de hilo jurídico conductor: el criterio decisivo para la definición de una rama del Derecho sería, después de todo, el de la existencia de un hilo jurídico conductor (en lugar de la existencia de principios propios). La dificultad no desaparecería, sin embargo, porque el concepto de hilo jurídico conductor no se presenta suficientemente compacto para sustituir, con ventaja, el recurso al criterio de los principios propios. Así que, de nuevo, la cuestión: ¿qué medida de hilo jurídico conductor se necesitaría para originar una rama del Derecho? Suponemos ser este tipo de interrogatorio el que refleja el núcleo de la cuestión de la creación científica de las ramas del Derecho, y cuya respuesta nos lleva a la primacía de los principios propios. Para la partición correcta (a fines de elaboración y aplicación) de las normas de Derecho es suficiente detectar principios generales que las dominen. Una vez logrado este objetivo, todo lo demás se vuelve secundario ${ }^{18}$.

Sin embargo, existen dificultades derivadas del aumento de complejidad de la vida social: en efecto, la materialización de estas directrices se presenta ciertamente difícil, al dibujar in concreto el mapa de las ramas del Derecho, debido, en primer lugar, a la sofisticación de la vida de la sociedad. Por otra parte, está

\footnotetext{
${ }^{17}$ Del mismo modo, por ejemplo, FERRAZ JR., que ve, como criterios para la autonomía científica de las ramas del Derecho, la determinación de un objeto propio y la de principios peculiares (FERRAZ, Tercio Sampaio Jr., Introdução ao Estudo do Direito: Técnica, Decisão, Dominação, $2^{\mathrm{a}}$ ed., Atlas, São Paulo, 1994, p. 146). Una posición que creemos próxima es la de Poletti, según el cual para que un campo jurídico pueda disfrutar de autonomía científica, tiene que cumplir con ciertos requisitos relacionados con el campo donde se centre, es decir, su objeto, el método propio, los principios generales extraídos del estudio sin ser confundidos con los de otras disciplinas (Polettı, Ronaldo, Introdução ao Direito, $3^{\text {a }}$ ed., Saraiva, São Paulo, 1996, p. 255).

${ }^{18}$ Es por eso que algunas diferencias entre particiones doctrinales son irrelevantes para el tratamiento adecuado del fenómeno jurídico (todas las que vengan a conducir, en última instancia, al reconocimiento de los mismos principios para las mismas normas).
} 
surgiendo una tendencia a la aparición de nuevas ramas, por lo general mediante una separación frente a las ramas ya establecidas; de ahí, cabe entonces preguntar: ¿si la materia-base es la misma, cuándo podrá decirse que la aparición de ciertos principios justificará la admisión de una nueva rama? ¿Cuántos principios tendrán de sumarse, para que se justifique el sacarse una determinada zona de materia de un bloque al cual pertenecía? Esa es la cuestión de las ramas nuevas, con respuestas delicadas y disidencias doctrinales fácilmente detectables.

Por otro lado, se detecta, en el "modo de operar" sobre estas cuestiones, algún intuicionismo: si vemos todo el universo de las normas de Derecho en términos de normas generales / normas especiales (lo que a nuestro juicio es perfectamente válido), podremos ver fácilmente que las ramas del Derecho corresponden, a fin de cuentas, a la agrupación de normas afines en cuanto a su especialidad; saber dónde poner el listón para definir el nivel de especialidad pertinente para la delimitación de las ramas del Derecho es, en última instancia, el problema; y creemos que la solución del mismo siempre termina pasando, en gran medida, por alguna dosis de intuición. Se le añade aun alguna convencionalidad; lo decimos, creyendo que nuestra posición en todo este asunto no debe calificarse de negativista, ya que intenta exponer fielmente la realidad jurídica (detectando hasta qué punto es posible hacerse estricta Ciencia); de hecho, suponemos deber reconocerse, sin pasión, que hay un inevitable quid de convencionalismo en el dibujo habitual del mapa de las ramas del Derecho (lo que no ofende incluso la Ciencia, a condición de respetarse el requisito esencial de la correcta identificación de los principios aglutinantes de las normas jurídicas) ${ }^{19}$.

En cualquier caso, y concluyendo, subrayamos que nos parece ser una posición realista la de no olvidar, en la delimitación de la dimensión de las ramas, el papel de un cierto intuicionismo: la intuición, "filtrada" por el espíritu de un científico, es un camino válido ${ }^{20}$, en un área donde los avances de la realidad son, ahora, quizás mayores que nunca ${ }^{21}$.

\footnotetext{
${ }^{19}$ Incluso nos preguntamos: ¿clasificaciones o tipologías? Y en efecto admitimos (aunque no suscribiendo esa opción) que, en lugar de clasificaciones de las ramas del Derecho, se pueda hablar de tipologías: las ramas del Derecho corresponderían a tipos, es decir, nacerían ramas donde, independientemente de otras consideraciones, se pudiesen delinear conjuntos de normas conocidas por su sumisión a determinados principios generales.

${ }^{20}$ Prueba del valor del intuicionismo es el hecho de que, a pesar de todo el debate doctrinal en torno a la segmentación del universo del Derecho, los autores ven a terminar, por lo general, en soluciones donde algunos datos tienden a mantenerse. Deben reconocerse, sin embargo, algunas limitaciones paracientíficas de segmentación; pero este reconocimiento no quiere decir que compartamos del "radicalismo" de autores que, como MaINGuY, consideran la división del Derecho en ramas como en gran medida arbitraria (Mainguy, Daniel, Introduction générale au droit, $3^{a}$ ed., Litec, Paris, 2002, p. 20).

${ }^{21}$ Por otra parte, esta opción se puede hacer sin temor, ya que la construcción científica del Derecho no se verá afectada por la dimensión de ramas elegida; la única consecuencia de las diferencias de
} 
III. Factores de uso común en la demarcación científica de las ramas del Derecho. Se han utilizado en la doctrina, para el dibujo científico de las ramas del Derecho, factores que podemos distribuir en dos especies: los factores materiales impuros y el factor material puro. En cuanto a los factores materiales impuros, son de señalar el factor de tendencia formal, el factor del sistema de inserción (o de origen), y el factor de la finalidad. Puede llamarse uno de ellos como factor de tendencia formal, porque la rama del Derecho se delinea, en sentido estricto, mediante una característica formal que tienen las respectivas normas: por ejemplo, son normas de Derecho Penal aquellas (y sólo esas) que califican ciertos actos como crímenes y establecen penas criminales y medidas de seguridad. Se utiliza también un factor inherente al origen de las normas (factor del sistema de inserción o de origen): así se delimita el Derecho Internacional Público, entendido como constituido por las normas que aparecen en la sociedad internacional. Por último, es mediante un factor de finalidad que se distingue el Derecho Procesal: es decisivo, ahora, el objetivo de las normas (hacen parte del Derecho Procesal las normas que se refieren a la aplicación del Derecho a través de la función judicial).

También entra en juego el factor material puro. Es sobre esta base que se edifica el Derecho Civil, entendido como el conjunto de normas que regulan las relaciones privadas comunes ${ }^{22}$.

La pluralidad de criterios lleva a superposiciones, que no son más que el resultado de interpenetraciones (interconexiones) entre ellos. Lejos de negar este hecho, tratando de "encajar" obligatoriamente todas las normas en un único "molde", creemos que es importante reconocer el hecho de que hay reglas "que pueden encajar" simultáneamente en más de una rama; y extraer, de ello, todas las consecuencias. De lo contrario, corremos el riesgo de ver calificada una misma norma como perteneciente a una determinada rama u otra, sin encontrar razón categórica para esa opción.

IV. Factores usualmente utilizados en la demarcación científica de las ramas del Derecho y principios generales caracterizadores de las ramas. Hemos dicho abundantemente que, a fines de un listado científico de las ramas del Derecho, el criterio definidor decisivo era la existencia de principios propios caracterizadores de cada rama. Se verifica, sin embargo, que los factores usualmente

dimensión es delinearse campos de análisis más grandes (más "macrojurídicos") o más pequeños (más "microjurídicos", en este específico sentido); las necesarias operaciones de interconexión se encargarán, después, de iluminar los posibles diferentes niveles, hasta cubrir el universo total del Derecho.

22 Han sido aun nombrados otros posibles criterios; en Portugal y, por ejemplo, FerreirA DA CUNHA indica tres elementos diferenciadores: los distintos sujetos o personas jurídicas, nuevos objetos, y relaciones jurídicas distintas (Ferreira da Cunha, Paulo, Pensar o Direito, Vol. II, Da Modernidade à Postmodernidade, Almedina, Coimbra, 1991, p. 115). 
utilizados para la delimitación de las ramas parecen, al menos para sectores del Derecho indudablemente grandes e importantes, hacer caso omiso de este criterio $^{23}$. ¿Si no hay contradicción, dónde está la explicación?

Es que la división del Derecho se fue haciendo, históricamente, con un principal sello de necesidad ("empujón" o dinámica) empírica"; y las ramas -especialmente las más antiguas- se fueron manteniendo sensiblemente conformes al dibujo original; contribuyeron para ello el peso de la tradición, la ausencia de daño de esa división para la Ciencia del Derecho, y la "revolución" que implicaría una total redefinición de los marcos "acomodadores" del mundo jurídico (de notar que los legisladores han a menudo seguido, a través de la codificación, la división doctrinal del Derecho).

\section{2. ¿El Derecho de los Museos tiene autonomía científica?}

I. Secuencia. Por su decisiva importancia en este estudio, partimos entonces del supuesto de que, para la demarcación científica de las ramas del Derecho, el criterio definidor decisivo es la existencia de principios propios caracterizadores de cada rama.

En consecuencia, nuestro análisis posterior se centrará en averiguar si el Derecho de los Museos contiene, o no, principios generales caracterizadores (teniendo en cuenta que no hay, para este conjunto de normas, otras condicionantes de segmentación científica).

Nuestra tarea se hace más fácil, porque la ley portuguesa ha consagrado, expresamente, la lista de principios generales moldeadores de este campo normativo. Es necesario por tanto pasarlos en revisión, evaluando de su naturaleza de principios generales caracterizadores (o no) del respetivo conjunto de normas.

II. El principio de la primacía de la persona. Según el principio de la primacía de la persona (letra a) del apartado 1 del artículo $2^{\circ}$ de la LM), los museos son vistos como instituciones esenciales para el desarrollo integral de la persona humana ${ }^{25}$ : el hombre es considerado como un ser eminentemente cultural, por lo que su acceso a los bienes culturales es una conditio sine qua non de su

\footnotetext{
${ }^{23}$ Se producen, de hecho, coincidencias y faltas de coincidencia: hay situaciones en las que la delimitación por dichos factores resulta coincidente con la aparición de principios propios (es el caso del Derecho Penal, por ejemplo); pero en otras situaciones -hay que reconocerlo- no existe coincidencia (¿dónde están, por ejemplo, los principios caracterizadores del Derecho Constitucional?...).

${ }^{24}$ Son expresivas las observaciones de CUNHA, para quien una rama del Derecho no se firma por registro, ni es bautizada con champán, o proclamada por un heraldo (Pensar o Direito..., cit., p. 112).

${ }^{25}$ Los museos necesitan una inversión en instalaciones y mano de obra que sólo se justifica en la creencia de que los museos tienen ciertos efectos en el público que los visita (Delicado, Ana, A Musealização da Ciência em Portugal, tesis doctoral, Fundação Calouste Gulbenkian-Fundação para a Ciência e a Tecnologia, Lisboa, 2009, p. 15).
} 
realización como persona jurídica "plena"; la importancia dada a los museos, traducida en la consagración jurídica de su carácter indispensable como medio de alcanzar la realización del hombre, se explica porque los museos personifican vehículos privilegiados de contacto con bienes culturales ${ }^{26}$.

La ley refuerza el citado vector, mediante una conexión expresa y directa de los museos con la concretización de los derechos fundamentales de los sujetos jurídicos; como los museos actúan en el ámbito de la cultura, queda claro que se deduciría, de aquí, la existencia de un derecho fundamental a la cultura ${ }^{27}$; y el cotejo de la parte final de la letra a) del apartado 1 del artículo $2^{\circ}$, con la letra b) del apartado 1 del artículo $3^{\circ}$ (ambos de la LM), permite explicar algo más: el citado derecho a la cultura se traduce en un derecho al disfrute cultural, pues que, por imposición de este último normativo, haz parte del concepto de museo la posibilidad de esa institución "proporcionar un acceso regular al público y promover la democratización de la cultura"28; puede incluso discernirse, más allá de la consagración de un derecho al disfrute cultural, y como se deduce de la citada combinación de disposiciones, un deber (a cargo de los museos) de fomento cultural.

Esta guía se presenta como un verdadero eje central en el dibujo del sistema jurídico de los museos, como el propio Gobierno quiso subrayar; puede así leerse que el "dibujo general del sistema jurídico de los museos portugueses tiene como una matriz que la dignidad de la persona humana implica el pleno desarrollo de su personalidad, atendida por la libertad de disfrute y creación cultural" y que los museos "son un instrumento clave para la protección y mejora del patrimonio cultural del pueblo portugués, que esta propuesta asume claramente como una de las principales tareas del Estado, de acuerdo con los principios fundamentales de la Constitución de la Republica"29.

\footnotetext{
${ }^{26}$ Este enfoque no debe, de hecho, ser olvidado; a pesar del correcto de los museos se centraren en la persona humana, alguien ha criticado, con razón, un exceso consistente en la sensación de que los museos no son, por lo tanto, acerca de objetos (KeEnE, Suzanne, Fragments of the World: Uses of Museum Collections, Elsevier Butterworth Heinemann, Oxford, 2005, p. 1).

${ }^{27}$ Acerca de la configuración y del marco del derecho fundamental a la cultura, véanse las notas breves pero recientes de Ress Novals, Jorge, Direitos Sociais: Teoria Jurídica dos Direitos Sociais enquanto Direitos Fundamentais, Wolters Kluwer (Coimbra Editora), Coimbra, 2010, nomeadamente pp. 41 nota (18), 54 y 344. El derecho a la cultura, especialmente en su dimensión de derecho fundamental social, participa de la consagración que ahora se reconoce a los derechos fundamentales sociales, los cuales se impusieron a pesar de sus críticos y tienen actualmente una total dignidad (FeRREIRA DA CUNHA, Paulo, Traité de droit constitutionnel, Buenos Books International, Paris, 2010, p. 182).

${ }^{28}$ Acerca de la vecina realidad española de los museos se ha hablado, aun recientemente, de un creciente disfrute, haciendo de ellos el espejo vivo de los cambios experimentados por una todavía joven democracia (Gómez MARTínez, Javier, Dos museologías: Las tradiciones anglosajona y mediterránea: diferencias y contactos, Trea, Gijón, 2006, p. 11).

${ }^{29}$ Propuesta de Ley Marco de los Museos Portugueses ("Proposta de Lei-Quadro dos Museus Portugueses"), cit., № 11 de la Exposición de Motivos ("Exposição de Motivos").
} 
¿Estaremos frente a un principio general caracterizador del Derecho de los Museos? Independientemente de la eventual autonomía de que goce el Derecho del Patrimonio Cultural (problema de que no cura este breve ensayo), lo cierto es que igual directriz genérica se encuentra en este último campo jurídico; basta tener en cuenta el apartado 2 del artículo $3^{\circ}$ de la "Ley del Patrimonio Cultural" 30 (LPC), que incumbe el Estado de cuidar del patrimonio cultural, y en particular, "como instrumento primacial de realización de la dignidad de la persona humana, objeto de derechos fundamentales". Por otra parte, un principio general de esta índole difícilmente sería capaz de limitar (o definir) una rama del Derecho, en un Estado democrático, porque la esencia misma de la democracia jurídico-política se basa, in toto, en la primacía de la persona humana, considerada como una razón de ser, y la base de construcción, del propio Estado (visto como un medio, si bien necesario, para garantizar la supervivencia del hombre, pero sin poder sobreponerse a la dignidad de éste -la cual tiene por misión garantizar y, deseablemente, ampliar-). Ya que, en la actualidad, el Estado portugués es un "Estado de Derecho democrático", en virtud del artículo $2^{\circ}$ de la Constitución de la República Portuguesa (CRP) y una república "basada en la dignidad de la persona humana" (artículo $1^{\circ}$ de la CRP), entra de lleno en los considerandos expuestos ${ }^{31}$.

III. El principio de la promoción de la ciudadanía responsable. Hay una conexión clara entre el principio de la promoción de la ciudadanía responsable (letra b) del apartado 1 del artículo $2^{\circ}$ de la LM) y el principio de la primacía de la persona (letra a) del apartado 1 del artículo $2^{\circ}$ de la LM); por otra parte, el texto de la ley plasma explícitamente aquella conexión, poniendo, en el núcleo del principio de la promoción de la ciudadanía responsable, la valorización de la persona y, por otra parte, consignando que los museos son herramientas indispensables en el ámbito del disfrute y creación cultural.

Pero el principio de la promoción de la ciudadanía responsable no es de confundir, por supuesto, con aquel otro; su área normativa diferencial se centra,

\footnotetext{
${ }^{30}$ Oficialmente nombrada como Ley que establece las bases de la política y el sistema de protección y valorización del patrimonio cultural (Lei que "estabelece as bases da política e do regime de protecção e valorização do património cultural") (Ley № 107/2001, del 8 de septiembre).

${ }^{31}$ Ya hace una década se decía, en términos generales, que la tendencia actual es reconocer que las normas constitucionales de consagración de derechos económicos, sociales y culturales no son una simple aleluya jurídica de inocuas declaraciones (MederRos, Rui, "A Carta dos Direitos Fundamentais da União Europeia, a Convenção Europeia dos Direitos do Homem e o Estado Português", in AAVV, Nos 25 Anos da Constituição da República Portuguesa de 1976: Evolução Constitucional e Perspectivas Futuras, Associação Académica da Faculdade de Direito de Lisboa, Lisboa, 2001, pp. 225-293, pp. 260261). Se añade que, en virtud del principio de la primacía de la persona, son necesarios equilibrios delicados, en primer lugar, entre la defensa y valorización del patrimonio cultural y la salvaguardia de otros bienes u valores constitucionales, como dice CaSAlta Nabals, José, cit., p. 22.
} 
como su nombre ("promoción") insinúa, en el fomento del empeño de todos los ciudadanos en la salvaguardia, enriquecimiento y difusión de los museos, como detentores de los bienes culturales: es importante decir que el Estado toma sobre sí la tarea de "Ilamar" a todos los ciudadanos a asumir una especie de corresponsabilidad jurídico-política en el marco "de la gestión" (en sentido amplio $)^{32}$ de los bienes culturales ${ }^{33}$; de acuerdo con los imperativos del principio de la promoción de la ciudadanía responsable, los museos son concebidos como vehículos de acción cultural, instituciones que contribuyen al desarrollo integral de la persona humana, constituyendo instrumentos que, incluso por medio de la promoción de la ciudadanía responsable, contribuyen a la consecución del derecho fundamental de disfrute y creación cultural previsto en el apartado 1 del artículo 78 de la CRP.

También fue esclarecedora la posición adoptada por el Gobierno en su propuesta de ley de los museos, al afirmar que esa propuesta "sostiene el punto de vista de la mejora del patrimonio cultural como un elemento de enriquecimiento de las personas, unificador de la identidad cultural común y factor de cohesión social, creando un marco legal de responsabilidad y colaboración con todos los agentes culturales en la aplicación de la política cultural indicada en el Programa del Gobierno"${ }^{\prime 34}$.

¿Estaremos frente a un principio general caracterizador del Derecho de los Museos? Debe responderse negativamente, por una vía muy lineal: es que el mismo principio se encuentra, en esencia, en el seno del Derecho del Patrimonio Cultural, traducido de forma inequívoca en el artículo 11 de la LPC. Establece, en efecto, esta disposición que "[t]odos tienen el deber de preservar el patrimonio cultural" (apartado 1), que "[t]odos tienen el deber de proteger y conservar el patrimonio cultural" (apartado 2), y que "[t]odos tienen el deber de valorizar el patrimonio cultural" (apartado 3). Descontando el (comprensible) hecho de que no se habla de un deber general (a cargo de los propios ciudadanos) de difusión

\footnotetext{
${ }^{32}$ Esta "gestión" se basa en la idea, aún más amplia y ya clásica, de que la participación representa una forma de ejercicio de la libertad y la libertad es un principio fundamental de la conformación de una verdadera democracia, como (citando J. Baptista Machado) escribió D'Oliveira Martins, Afonso, "Constituição, Administração e Democracia", in AAVV, Nos 25 Anos da Constituição da República Portuguesa de 1976: Evolução Constitucional e Perspectivas Futuras, Associação Académica da Faculdade de Direito de Lisboa, Lisboa, 2001, pp. 461-504, p. 498.

${ }^{33}$ Esta es una opción de ningún modo exclusiva; puede indicarse, como mero ejemplo, la llamada Nueva Museología latinoamericana, que busca integrar a las comunidades como participantes en la vida de los museos (YúdicE, George, "Museu molecular e desenvolvimento cultural", in J. Do NasCimento JUNIOR (org.), Economia de museus, Ministério da Cultura-Instituto Brasileiro de Museus, Brasília, 2010, pp. 21-52, p. 22).

${ }^{34}$ Propuesta de Ley Marco de los Museos Portugueses ("Proposta de Lei-Quadro dos Museus Portugueses"), cit., № 15 de la Exposición de Motivos ("Exposição de Motivos").
} 
del patrimonio cultural (pues que un tal deber sólo tiene sentido en el contexto, más estricto, de los varios posibles medios de difusión cultural), se impone la conclusión de la sustancial coincidencia de ambos principios.

IV. El principio de servicio público. La afirmación de los museos como "instituciones abiertas a la sociedad", formulación con la cual la ley determina el contenido del principio de servicio público (letra c) del apartado 1 del artículo $2^{\circ}$ de la $\left.L M\right)^{35}$, es traducción de la idea de un marcado valor jurídico-social de los bienes culturales.

Esta óptica de enfoque de los museos es algo opuesta a una idea centrada en la propiedad o posesión de los bienes culturales; el propietario o poseedor de estos (en la típica hipótesis, el museo) no puede utilizarlos visando sus propios intereses egoístas: el museo está más bien al servicio de la comunidad, cuyos intereses debe llevar adelante ${ }^{36} ;$ y téngase en cuenta que, si esta idea no es muy innovadora en lo de los museos públicos, adquiere, sin embargo, un significado y alcance más notorios para los museos privados, también cubiertos por el mismo principio. Es, en definitiva, proscrito el ensimismamiento de los museos, que no pueden ser "torres de marfil" estáticas, inmóviles ${ }^{37}$ y sólo accesibles a unos pocos privilegiados (o iniciados); el museo tiene que ser una fuerza viva, actuante y dinámica, en un auténtico "conjunto de vasos comunicantes" con el entorno social que lo abarca ${ }^{38}$.

\footnotetext{
${ }^{35}$ Sobre la importancia de una directriz paralela se declaró, en relación con el ordenamiento jurídico español, que las autoridades gubernamentales han favorecido, en muchos casos y por encima de otros criterios, la idea de los museos como instituciones comprometidas con la sociedad en su vocación de servicio público (Villarroya Planas, Anna, y Escardíbul Ferrá, Josep-Priol, "Panorámica de la situación museística en España", in J. DO NASCIMENTO JUNIOR (org.), Economia de museus, Ministério da CulturaInstituto Brasileiro de Museus, Brasília, 2010, pp. 73-98, p. 74).

${ }^{36}$ Los museos están lejos de ser neutrales en cuanto a la realidad, pues (re)definen esta realidad en el contexto de su propia ideología (Semedo, Alice, "Introdução", in A. Semedo y J. T. Lopes (coord.), Museus, discursos e representações, Afrontamento, Porto, 2005, pp. 13-26, p. 14). Relacionada con esta idea es la de que las "colecciones de un museo son una expresión del patrimonio cultural y natural de las comunidades de las que proceden", por lo que "no sólo rebasan las características de la mera propiedad, sino que además pueden tener afinidades muy sólidas con las identidades nacionales, regionales, locales, étnicas, religiosas o políticas" (Consejo Internacional de Museos (ICOM), Código de Deontología del ICOM para los Museos, cit., p. 9).

${ }^{37}$ Los museos ya no corresponden a la jerarquía armoniosa de antaño en la que todo estaba en su lugar, retirado de la historia y del cuestionamiento (TEIXEIRA LOPES, João, "Notas conclusivas. Os museus como terceiras culturas", in A. SEMEDo y J. T. Lopes (coord.), Museus, discursos e representações, Afrontamento, Porto, 2005, pp. 197-199, p. 198).

${ }^{38}$ En esta visión moderna, que trasciende las fronteras, los museos van a pasar a ser unas instituciones culturales al servicio de la sociedad, tal como lo define la Nueva Museología (Arrieta Urtizberea, Iñaki, "La Nueva Museología, el patrimonio cultural y la participación ciudadana a debate", in I. ArRIETA URTizBerea (ed.), Participación ciudadana, patrimonio cultural y museos: Entre la teoría y la praxis, Universidad del País Vasco, Bilbao, 2008, pp. 11-22, p. 15, consultado el 10 de septiembre de 2010,
} 
Y esta postura que se asigna a los museos representa la otra cara del disfrute, por la sociedad, de los bienes culturales albergados en los museos: éstos deben estar disponibles para permitir ese disfrute ${ }^{39}$, es decir, tienen que asumir un "espíritu de misión" que pasa por una vivencia moldeada en favor de la sociedad ${ }^{40}$. Por otra parte, como detentores de bienes culturales, los museos se integran en un papel actual del patrimonio cultural, que, como ha sido reconocido en el mundo desarrollado, genera recursos, desarrollo, turismo, actividad económica y más ${ }^{41}$.

Debemos preguntarnos si este principio general es caracterizador del Derecho de los Museos; y la respuesta es, nuevamente, negativa. La "apertura" de los museos a la comunidad tiene, como magno objetivo, facultar el disfrute de los bienes culturales a los ciudadanos. Pero el derecho al disfrute, con las inherentes obligaciones a cargo de los detentores de los bienes culturales, rige también, como directriz genérica, en el seno del Derecho del Patrimonio Cultural. En virtud del apartado 1 del artículo $7^{\circ}$ de la LPC, "[t]odos tienen derecho al disfrute de los valores y bienes que conforman el patrimonio cultural". Y, también aquí, se cubre el universo de los bienes culturales públicos y privados: si nada de especial se ofrece decir sobre los primeros (por razones obvias), la ley se preocupa con incluir expresamente los segundos, al prever

en <http://www.argitalpenak.ehu.es/p291-content/es/contenidos/libro/se_indice_arte/es_arte/adjuntos/ particip.pdf $>$ ).

${ }^{39}$ En el lenguaje de la propuesta de Ley de los Museos, éstos "ya no tienen como único objetivo la conservación y exhibición de obras de arte y comenzaron a preservar la memoria colectiva en formas más amplias, preservando y exhibiendo la historia de las comunidades, la evolución de las ciencias y de las técnicas, las artes y artesanías tradicionales, las formas de vida de los pueblos, especialmente los que viven en los territorios circundantes" (Propuesta de Ley Marco de los Museos Portugueses, "Proposta de Lei-Quadro dos Museus Portugueses", cit., № 2 de la Exposición de Motivos, "Exposição de Motivos"). Está en la misma línea que el Consejo InTERnACIONAL De Museos, según lo cual los museos "tienen contraídas obligaciones especiales para con la sociedad por lo de la protección, accesibilidad e interpretación de los testimonios esenciales que han acopiado y conservado en sus colecciones" (CONSEJO InTERnacional de Museos (ICOM), Código de Deontología del ICOM para los Museos, cit., p. 6).

${ }^{40}$ El principio de servicio público refleja la idea, más amplia, de que el patrimonio cultural es un tema que no puede dejar de referirse a todos y cada uno de los miembros de la comunidad (CASAlta Nabals, José, cit., p. 31).

${ }^{41}$ Hernández Ramírez, Macarena y Ruiz Ballesteros, Esteban, "El patrimonio como proceso social. Intervención, desarrollo y consumo del patrimonio minero en Andalucía", in I. Arrieta Urtizberea (ed.), Participación ciudadana, patrimonio cultural y museos: Entre la teoría y la praxis, Universidad del País Vasco, Bilbao, 2008, pp. 129-147, p. 140, consultado el 10 de septiembre de 2010, en <http://www. argitalpenak.ehu.es/p291-content/es/contenidos/libro/se_indice_arte/es_arte/adjuntos/particip.pdf $>$. En cuanto al turismo, en particular, se observa que, en la motivación de los visitantes de los museos, hay una búsqueda de momentos de placer añadidos a la posibilidad de aprender y de nuevas experiencias (Marandino, Martha, Mortara Almeida, Adriana y Alvarez Valente, Maria Esther, "Introdução", in M. Marandino, A. M. Almeida y M. E. A. Valente (org.), Museu: lugar do público, Fiocruz, Rio de Janeiro, 2009, pp. 9-13, p. 9). 
también el "disfrute por terceros de bienes culturales, cuyo soporte constituya objeto de propiedad privada u otro derecho real de goce" (apartado 2 del artículo $7^{\circ}$ de la LPC ${ }^{42}$.

V. El principio de la coordinación. Otro de los principios generales del Derecho de los Museos es el principio de la coordinación, que requiere una articulación entre las líneas-guías de estructuración del mundo de los museos y las líneas-guías de materias distintas, siendo que la ley elige, entre estas últimas, otros nichos culturales, la educación ${ }^{43}$, la ciencia ${ }^{44}$, la ordenación del territorio, el medio ambiente y el turismo (letra $d$ ) del apartado 1 del artículo $2^{\circ}$ de la LM).

La ratio de este principio se conexiona a la conveniencia (o incluso necesidad) de maximizar semejanzas y reducir desajustes, si no el imperativo de lograr compatibilidades y evitar paradojas (o contradicciones); de un punto de vista sustancial, no es obviamente indiferente la elección de las materias elegidas como objeto de este principio general; se trata de sectores con conexiones más profundas a los bienes culturales (las cuales son fáciles de vislumbrar): así es que la educación se traduce, en parte, en la introducción guiada al conocimiento de bienes culturales; que la ciencia es, en considerable medida, el propio conocimiento sistematizado y metodológicamente validado de bienes culturales; que la ordenación del territorio influye, y es influida, por la distribución geográfica de los bienes culturales; que el medio ambiente tiene interacción con la ubicación y características de los museos (y hasta con el propio acervo de estos, incluso condicionándolo); y que el turismo comporta, en la actualidad (de manera

\footnotetext{
${ }^{42}$ Añadiendo, por supuesto, en respeto por el derecho fundamental a la propiedad privada, que, en estos casos, este disfrute "depende de los medios de difusión concertados entre la administración del patrimonio cultural y los titulares de las cosas" (segmento final del apartado 2 del artículo $7^{\circ}$ de la LPC).

${ }^{43}$ En cuanto a la relación entre la cultura y la educación, vale la pena recordar que el tema de la democratización del acceso al consumo cultural está en la agenda actual, como, por ejemplo, destacó Abreu, Regina, "A cultura do mecenato no Brasil: uma utopia possível?", in J. Do Nascimento Junior (org.), Economia de museus, Ministério da Cultura-Instituto Brasileiro de Museus, Brasília, 2010, pp. 163-201, p. 167.

${ }^{44}$ En la economía de la propuesta de Ley de los Museos, el Gobierno ha dedicado un lugar importante a la educación y a la ciencia, señalando que la "conexión central del dominio museológico con la investigación y la educación implica que se prestará especial atención a la escuela, tanto en lo referente a las universidades como en lo referente a entidades situadas en otros niveles de la educación, con vocación, por lo tanto, para niveles de formación diferentes y diferentes grupos de edad"; y agregó, respecto a la educación, una preocupación especial y simultánea de depuración de excesos, importando "evitar el proceso de masificación detectable en el desarrollo de la relación entre los museos y las escuelas, que necesita ser corregido, pues de lo contrario se acabaría subvirtiendo la conexión deseada precisamente en edades en las que esta podría ser más prometedora" (Propuesta de Ley Marco de los Museos Portugueses, "Proposta de Lei-Quadro dos Museus Portugueses", cit., № 8 de la Exposición de Motivos, "Exposição de Motivos").
} 
ampliamente reconocida), una no despreciable dosis (o vector) cultural, hasta el punto de poder incluso hablarse de un "turismo cultural".

Una vez más resulta, por otra parte, que no estamos ante un principio general caracterizador del Derecho de los Museos. Compulsando la letra c) del artículo $6^{\circ}$ de la LPC, que además se refiere expresamente al principio de la "coordinación", se descubre a simple vista sencilla, casi con un golpe, que este último -un principio general del Derecho del Patrimonio Cultural-presenta un contenido coincidente, en su esencia, con el contenido del citado principio general del Derecho de los Museos.

VI. El principio del transversal. El denominado principio del transversal impone la agregación de los bienes culturales, con independencia de su titularidad institucional, procedencia geográfica o naturaleza temática, en un mismo universo de tratamiento jurídico, con el fin de generar y dar un marco normativo adecuado a esa polifacética realidad; y es formalmente consagrado en la letra e) del apartado 1 del artículo $2^{\circ}$ de la LM.

La indicada línea de indistinción jurídica es asumida sin ambigüedades, en lo que concierne a la cuestión de la propiedad institucional, en la propuesta de ley de los museos, donde se registró que el concepto de museo "se presenta en esta ley con un sentido prospectivo de innovación, anclado en las perspectivas internacionales en este campo y en el conocimiento de la realidad portuguesa, y es un instrumento de aplicación del régimen jurídico que parte de la consideración sustancial de las funciones museológicas, con independencia de la propiedad pública o privada" 45 . Es más: el Gobierno no ha dejado de "subrayar la preocupación claramente afirmada de asegurar la unidad de destino común a los bienes culturales que justifiquen la creación de nuevos museos o la reestructuración de otros ${ }^{\prime 4}$.

El transversal, visto en esta perspectiva, no es más que el reconocimiento (y extracción de consecuencias) de la unidad profunda de los bienes culturales (a pesar de sus diferentes configuraciones materiales específicas), reclamando una atención jurídica compleja y unitaria como forma única de reflejar y disciplinar normativamente aquella unidad profunda.

Tal y cual los anteriores, este principio no se perfila también como un principio general caracterizador del Derecho de los Museos, y una inspección sumaria a la LPC es suficiente para llegar a esta conclusión. Vale, como razonamiento suficiente, la amplitud misma de la LPC, que considera que componen

\footnotetext{
45 Propuesta de Ley Marco de los Museos Portugueses ("Proposta de Lei-Quadro dos Museus Portugueses"), cit., № 11 de la Exposición de Motivos ("Exposição de Motivos").

${ }^{46}$ Propuesta de Ley Marco de los Museos Portugueses ("Proposta de Lei-Quadro dos Museus Portugueses"), cit., № 15 de la Exposición de Motivos ("Exposição de Motivos").
} 
el patrimonio cultural "todos los bienes que, siendo testimonios con valor de civilización o de cultura con pertinencia cultural relevante, deban ser objeto de especial protección y valorización" (apartado 1 del artículo $2^{\circ}$ de la LPC). Es esta indistinción de los bienes culturales que acaba por reflejar, en otras palabras, la directriz del "transversal" moldeadora del Derecho de los Museos; quizá con un alcance algo más amplio, la directriz contenida en el Derecho del Patrimonio Cultural se alimenta, en su núcleo, de la fuente de la unidad de los bienes culturales subyacente al principio del transversal del Derecho de los Museos.

VII. El principio de la información. La ley portuguesa incluye también, como principio general del Derecho de los Museos, el principio de la información, consistente en la "recopilación y difusión sistemática de datos sobre los museos y el patrimonio cultural", teniendo como ratio "la finalidad de permitir en tiempo útil la más amplia difusión y el intercambio de conocimientos, a nivel nacional e internacional" (letra $f$ ) del apartado 1 del artículo $2^{\circ}$ de la LM).

De inmediato se ve, con sólo leer el inicio del precepto, que estas operaciones tienen por objeto, sin distinción, los propios museos y los bienes culturales (el "patrimonio cultural", como se expresa la ley); esta referencia legal al patrimonio cultural, hecha en la Ley Marco de los Museos, alerta fatalmente al intérprete: el principio transcripto, en lugar de exclusivamente aplicable en el seno del Derecho de los Museos, se aplica también en última instancia al patrimonio cultural en general, en una clara extrapolación sistemática del proclamado ámbito material de esta ley. Y las sospechas del intérprete respeto a esa extrapolación vienen a confirmarse mediante la consulta de la LPC, pues que se consagra en esta el principio general de la información, a saber, la obligación de "recolección sistemática de datos" y de permitir el acceso a los mismos "a los ciudadanos y organismos interesados como a las organizaciones internacionales competentes" (letra $f$ ) del artículo $6^{\circ}$ de la LPC); fácilmente se ve que, descontadas las diferencias de estilo literario, el contenido normativo de este principio es perfectamente paralelo al constante de la Ley Marco de los Museos (Derecho de los Museos), y rige por lo general (así lo determina su inserción sistemática) en el campo del patrimonio cultural (Derecho del Patrimonio Cultural).

VIII. El principio de la supervisión. Forma parte también, del conjunto de principios generales expresamente puestos en la Ley Marco de los Museos portugueses, el principio de la supervisión, en virtud del cual inciden sobre el Estado los deberes "de la identificación y fomento de procesos de buenas prácticas museológicas, de acciones promotoras de calificación y buen funcionamiento de los museos y de medidas para impedir la destrucción, pérdida o daños de los bienes culturales incorporados en aquellos" (letra g) del apartado 1 del artículo $2^{\circ}$ de la LM). 
El contenido de esta disposición sugiere firmemente que ella se limita al Derecho de los Museos; se vuelve entonces particularmente relevante la cuestión de saber si el mencionado normativo consustancia, o no, un principio general caracterizador del Derecho de los Museos.

Buscando la ratio del precepto, se descubre que las obligaciones en él mencionadas tienen como objeto la mejora del tratamiento de los bienes culturales; los museos son vistos como instituciones especialmente concebidas para, a través de ellas, se alcanzar aquel desiderátum: las "buenas prácticas museológicas", el "buen funcionamiento de los museos", conducirán a (o pretenderán) garantizar la maximización de la utilidad social de los bienes culturales; es decir: los museos son vistos como una herramienta, un instrumento (aunque muchísimo idóneo) al servicio de los bienes culturales, que son la esencial (sino exclusiva...) razón de ser de aquellos. Recorriendo un camino diferente de razonamiento, se llega a la misma conclusión de la inadecuación (o más bien imposibilidad) de considerar el principio en cuestión como un principio general caracterizador del Derecho de los Museos; de hecho, difícilmente podría reconocerse tal calificación a un comando jurídico que, simplemente, establece obligaciones para el correcto funcionamiento, y la mejora del funcionamiento, de una institución, aunque mediante una práctica continuada (y aunque incluso intensiva...). Y hay, por otra parte, una contraprueba de lo que acabamos de concluir: en sede de los "principios básicos", la LPC incumbe al Estado de la salvaguardia (o protección) y valorización del patrimonio cultural, calificando expresamente como "deber" de las personas colectivas públicas territoriales el "conocimiento, estudio, protección, valorización y difusión del patrimonio cultural" (artículo $3^{\circ}$, apartado 3 de la LPC); es así un principio general del Derecho del Patrimonio Cultural la grande y dinámica atención (y actividad) dedicada a la existencia y "vida" de los bienes culturales, lo que es decir, que la atención al mismo tiempo votada a los museos chapuza y bebe de esta postura básica, presentándose al final como un resultado de dicha postura.

IX. El principio de la descentralización. En la lista de principios generales del Derecho de los Museos también se incluye el principio de la descentralización, cuya formulación, en la Ley Marco de los Museos, se limita (literalmente) a la "valorización de los museos municipales y su papel en el acceso a la cultura" (letra $h$ ) del apartado 1 del artículo $2^{\circ}$ de la LM).

La descentralización cultural así puesta, con el énfasis centrado en las personas jurídicas que son los municipios ${ }^{47}$ (o sea, reportada al nivel municipal),

\footnotetext{
${ }^{47}$ El municipio es, en el concepto clásico, la autarquía local que tiene como objetivo defender los intereses propios de la población residente en el espacio territorial concejil, a través de los órganos representativos elegidos por ella (Freitas do Amaral, Diogo, Curso de Direito Administrativo, Vol. I, $3^{\mathrm{a}}$ ed., 2006, $4^{\mathrm{a}}$ reimpresión, Almedina, Coimbra, 2010, p. 526).
} 
consustancia una opción legal de cuya adecuación no cabe aquí analizar, por comprensibles razones. Habrá surgido, según el Gobierno, en respuesta a la situación de hecho del "desarrollo cada vez mayor del mundo museológico municipal, que supera considerablemente el de los establecimientos dependientes de la administración pública central", por lo que "estamos asistiendo a un desplazamiento para el ámbito municipal de una parte sustancial de los problemas que se deben enfrentar en esta área", lo que habrá obligado a "renovar el marco de la relación entre administración central y local"48.

Hay que registrar únicamente que, una vez más, no estamos delante de un principio general caracterizador del Derecho de los Museos. Merece poco retraso la prueba de lo que decimos: es casi suficiente poner en juego la parte final del apartado 3 del artículo $3^{\circ}$ de la LPC, que determina que es "deber del Estado, de las regiones autónomas y de las autarquías locales" la conservación, gestión y valorización del patrimonio cultural. Como se ve, la pauta de la descentralización impregna, en esos términos, todo el universo portugués del patrimonio cultural ${ }^{49}$ : no se circunscribe al fenómeno museológico, sino que es un atributo de una "forma de estar" nacional ante la figura jurídica de los bienes culturales.

X. El principio de la cooperación internacional. Hay por último una referencia expresa, en la Ley Marco de los Museos portugueses, al principio de la cooperación internacional (letra i) del apartado 1 del artículo $2^{\circ}$ de la LM). Fácilmente se ve que hay, detrás de este orden legal, un claro interés en el intercambio internacional de esfuerzos y experiencias, justificado por el Gobierno con el hecho de que "desde el siglo XIX, la evolución de la realidad museológica portuguesa presenta claro paso con la realidad internacional, revelando así un clima de apertura naturalmente beneficioso" ${ }^{\prime \prime 50}$.

Es curiosamente un principio general que contiene dos zonas normativas aparentemente especiales, incrustadas sobre un marco normativo genérico. Para mejor comprensión de lo afirmado, nada como transcribir el propio dispositivo de ley, que incluye en este principio el "deber de colaboración, especialmente

\footnotetext{
${ }^{48}$ Propuesta de Ley Marco de los Museos Portugueses ("Proposta de Lei-Quadro dos Museus Portugueses"), cit., № 3 de la Exposición de Motivos ("Exposição de Motivos").

${ }^{49}$ En el fondo yace la idea de que pueden atribuirse a la descentralización, en términos jurídicoadministrativos generales, aspectos positivos y negativos, pero que las ventajas superan a las desventajas, porque los límites de la descentralización mantienen sus inconvenientes dentro de lo aceptable, mientras que la obtención de sus ventajas es incompatible con soluciones que la aparten (REBELO DE Sousa, Marcelo y Salgado de Matos, André, Direito Administrativo Geral, Vol. I, $3^{\text {a }}$ ed., Introdução e Princípios Fundamentais, Dom Quixote, Alfragide, 2008, p. 148).

${ }^{50}$ Propuesta de Ley Marco de los Museos Portugueses ("Proposta de Lei-Quadro dos Museus Portugueses"), cit., № 7 de la Exposición de Motivos ("Exposição de Motivos").
} 
con museos de países de habla oficial portuguesa", al cual se añade el deber de "fomentar la cooperación con organismos internacionales con intervención en el área de la museología"; los mencionados deberes tienen, como sujeto pasivo directo, el Estado portugués, y parecen, en buena interpretación jurídica, presuponer una zona de obligaciones subyacentes más amplia.

Así, considerando el primer de los citados deberes, es legítimo preguntarse: ¿no impondrá la ley un genérico deber de colaboración con museos de cualquier país? Y parece que la conclusión es afirmativa: en primer lugar, porque el elemento literal así lo inculca, al hablar de un deber de cooperación "especialmente con museos de habla oficial portuguesa" ${ }^{51}$, lo que presupone un deber de colaboración (no especial) con otros museos extranjeros; por otra parte, y en la óptica del elemento racional de la interpretación, no se ve por qué habría que contrariarse la inferencia derivada del texto de la ley, dada la economía de todo el precepto.

Pasemos ahora al segundo de los previstos deberes, o sea, al deber de fomento ("fomentar la cooperación con organismos internacionales con intervención en el ámbito de la museología"): aunque este punto es menos claro, parece que el intérprete puede, al menos, preguntarse si no hay, por detrás de este segmento normativo, una obligación más amplia de fomento de la colaboración no sólo con organismos internacionales, pero además con organismos nacionales (públicos) extranjeros; por las limitaciones dimensionales de este estudio no cabe desarrollar el tema, que no tiene importancia para nuestras conclusiones.

Es la hora de, por última vez, hacer la pregunta directamente pertinente a los fines de esta investigación: ¿estamos, o no, ante un principio general caracterizador del Derecho de los Museos? Se repite el tipo de respuesta dada a las paralelas preguntas anteriores, es decir, una respuesta de naturaleza negativa. ¿Y cuál es ahora su fundamento? Es la existencia de un principio general de "cooperación internacional", en la letra i) del artículo $6^{\circ}$ de la LPC, que tiene un contenido alineado, en el fondo, con el homónimo principio de la Ley Marco de los Museos portugueses; más precisamente, y en los términos de su redacción, se impone allí, al Estado portugués, "reconoce[r] y da[r] efectividad a los deberes de colaboración, información y asistencia internacional". Si bien es cierto que se justificarían algunas reflexiones sobre el alcance exacto del transcripto comando del Derecho del Patrimonio Cultural, parece difícil no tener que declararse que, desde un punto de vista del contenido, parece más amplio

\footnotetext{
${ }^{51}$ El especial deber de cooperación internacional con museos de Estados de habla oficial portuguesa se conecta al interés particular del patrimonio cultural portugués compartido por los pueblos de habla portuguesa, debido a que se expresan en el idioma portugués y tienen capítulos de la historia común con Portugal, como, por ejemplo, pone de relieve CASAlta Nabals, José, cit., $2^{a}$ ed., Almedina, Coimbra, 2010, p. 121.
} 
que el comando correspondiente del Derecho de los Museos; y puede incluso afirmarse que, en el circulo normativo del primero, cabe de lleno el imperativo del segundo (así configurado como un núcleo normativo menos extenso).

\section{El Derecho de los Museos y la autonomía didáctica}

\subsection{Una aproximación al problema general del marco didáctico}

Se dice que una determinada área del Derecho tiene autonomía didáctica, cuando existen razones justificativas de la conveniencia, o necesidad, de ser objeto de una enseñanza independiente.

Hay posibles faltas de coincidencia entre ramas didácticas y ramas científicas; las ramas del Derecho, científicamente delimitadas, tienen una dimensión variada, con notables diferencias de extensión de contenido entre ellas; por lo tanto, las necesidades o conveniencias de orden didáctica conducen, a veces, a estudiar por separado zonas del Derecho que pueden no corresponder a ramas en el sentido científico ${ }^{52}$.

Pese a lo dicho, la coincidencia didáctica y científica se corresponde con el marco natural, o sea, existe una innegable tendencia al acercamiento entre los campos definidos por los criterios de autonomía científica y de autonomía didáctica. Lo que no resulta raro: la enseñanza del Derecho es la enseñanza de la Ciencia Jurídica; y ésta se hace mediante la disposición del material jurídico en bloques lógicos, hasta llegar a la delineación de un todo; este todo se organiza según "estantes" orientadoras, es decir, de acuerdo con principios de amplitud progresiva (principios de amplitud cada vez más grande); y así sucesivamente, hasta culminar en el descubrimiento de los principios fundamentales del Derecho (tomando la expresión en este sentido convencional), que forman la cúpula normativa del ordenamiento jurídico y constituyen -en conformidad-el polo unificador, explicativo y justificador de todo el edificio científico-jurídico. Por lo tanto, es natural y fácilmente comprensible que, cuando no haya otros intereses reclamando orientación distinta, se haga corresponder el ministerio didáctico a la edificación científica.

Se añaden, a todo lo anterior, las especificidades de materias y especificidades tendenciales concomitantes de principios generales: es que las diferencias entre las materias (de la vida) objeto de regulación por el Derecho llevan, a su vez y no raro, a un concomitante desarrollo de principios generales propios de cada

\footnotetext{
52 Sea porque cubren un espacio normativo más pequeño (piénsese, por ejemplo, en el Derecho Fiscal, de cara al Derecho Financiero), sea porque cubren un espacio normativo más amplio (piénsese, v.gr., en el Derecho Intertemporal, estudiado habitualmente junto a otras materias jurídicas generales, o entonces conjuntamente con una breve alusión al Derecho Internacional Privado y/o estudiado con materias de Derecho Civil).
} 
materia (reclamados por la especificidad de ésta); y así se cierra un círculo de tendencial coincidencia entre autonomía científica y autonomía didáctica ${ }^{53}$.

\subsection{La autonomía didáctica del Derecho de los Museos}

Puesto que un conjunto de normas jurídicas tiene autonomía didáctica cuando, a efectos de enseñanza, puede (o debe o hay ventajas objetivas en) ser objeto de enseñanza separada, es justo decir que el Derecho de los Museos cuenta con autonomía didáctica.

La enseñanza de la regulación jurídica de los museos es susceptible de un trato curricular distinto, en los programas de enseñanza del Derecho; y más: sólo así puede realmente darse, a los estudiantes, una visión institucional específica de la realidad jurídico-museológica. El autor de estas líneas ha podido comprobarlo, al impartir el módulo de Derecho de los Museos de la asignatura de Organización y Gestión de Museos del Máster en Museología de la Universidad de Porto (Portugal).

Se refleja en el ámbito jurídico, por otra parte, la naturaleza plural del estudio de la Museología, que llama a la confluencia de varias especies de conocimientos, girando su cemento aglutinador alrededor de la realidad "museo"; es el museo, como institución, que polariza también, en el ámbito del Derecho, el flujo de conocimientos jurídicos que deben ser seleccionados y transmitidos a los estudiantes de la institución jurídica llamada museo: en el plan didáctico, y en suma, estos son los términos y el significado de la autonomía del Derecho de los Museos.

\section{El Derecho de los Museos y la autonomía práctica}

\subsection{Una aproximación al problema general del marco práctico}

Cuando se dice que un área particular del Derecho tiene autonomía práctica, quiere decirse que hay razones pragmáticas que requieren o imponen un tratamiento separado. Debe profundizarse un poco esta afirmación.

Tomamos el "practicismo" como utilitarismo didáctico-expositivo: la alusión a la categoría denominada como autonomía práctica traduce para nosotros, en

\footnotetext{
${ }^{53}$ No olvidemos, sin embargo -y como nota complementar- el subrayar de la referencia al término tendencial; lo que se traduce, después de todo, en recordar lo que hemos dicho, a principios de este punto, acerca de los casos en los que razones particulares conducen a la falta de coincidencia entre zonas jurídicas edificadas con base en criterios científicos y zonas jurídicas edificadas con base en criterios didácticos. Y más: es incluso arriesgado hacer evaluaciones de naturaleza cuantitativa; en un cualquier país, en virtud de la difusión de estudios jurídicos para apoyar formaciones académicas de otra (y variada) naturaleza, nada garantiza que el conjunto de las organizaciones curriculares que integren Unidades de Derecho tenga que reflejar, incluso en el futuro, una situación final positiva de situaciones de coincidencia entre recortes organizativos jurídico-científicos y jurídico-didácticos.
} 
primer lugar, una manera de simplificar la presentación de las clasificaciones materiales del Derecho, evitando tener que entrar en las complejas investigaciones exigidas en relación con un criterio científico o aun con un criterio didáctico; están, pues, en juego, en un primer sentido, razones de naturaleza utilitarista-expositiva (que, si aplicadas al caso de la enseñanza -por ejemplo, de una asignatura cuyo objeto sean estas temáticas- nos atrevemos a llamar "razones de naturaleza didáctico-utilitaria").

Consideramos el practicismo, en segundo lugar, como el alejamiento de vectores científicos o de vectores didácticos: en efecto no abarcamos sólo, en la categoría residual que llamamos "autonomía práctica", el marco panorámico jurídico resultante de las razones expuestas. Más allá de ellas, creemos que pueden etiquetarse como de autonomía práctica los criterios que llevan a la agrupación de normas en grandes conjuntos (o bloques), en virtud de razones que abstraigan de preocupaciones de naturaleza científica o didáctica (las cuales sólo podrán, a lo mejor, entrar accidentalmente en consideración a efectos de la repartición de bloques jurídicos así hecha $)^{54}$. Tomando ejemplos de este último vector, se constata que hay campos normativos que se dibujan, en la vida jurídica, por razones más o menos atípicas, incidentales o circunstanciales ${ }^{55}$.

${ }^{54}$ Las razones pueden ser, incluso, concernientes a la vida de los profesionales (jueces, abogados...), relativamente a la cual, como por ejemplo dice PoletTı, la especialización profesional de los hombres que manejan el Derecho parece inevitable (cit., p. 255).

${ }_{55}$ Pensemos, en lo que respecta a la realidad jurídica portuguesa actual, en las normas contenidas en el Código de la Circulación ("Código da Estrada"): su aglutinación en un Código lleva a que constituyan, al menos formalmente, un bloque distinto; pero, fuera de esta aglutinación práctica (es decir, desde el punto de vista científico), se pregunta si es posible hablar de un Derecho del Tránsito (que podría también llamarse Derecho de la Circulación), como rama autónoma. Consideraciones similares (aunque no necesariamente por razones similares) pueden hacerse acerca de otros bloques normativos, como los correspondientes a expresiones tales que Derecho Europeo o Derecho de la Informática, por citar dos ejemplos situados en zonas y/o planes muy diferentes: así y en lo que respeta al Derecho de la Informática, MAINGUY, por ejemplo, dice que es difícil de encajar esta materia (tomada por él como de naturaleza jurídico-privada) en una de las ramas clásicas del Derecho, pareciendo no considerarla, por lo tanto, como consustanciando una rama (cit., p. 21). Mucho más complicada de calificar es, además, la alusión a un Derecho de los Negocios: BeIGNIER y BLÉrY, por ejemplo, encajan en el grupo de autores que consideran el Derecho de Negocios como una verdadera rama del Derecho, viéndolo como un campo que sucede al antiguo Derecho Comercial, envolviéndolo (BEIGNIER, Bernard y BLÉRY, Corinne, Manuel d'introduction au droit: Première année de licence-Premier semestre, Presses Universitaires de France, Paris, 2004, p. 106; vide también p. 107). MaInGuY, a su vez, afirma que se habla con más facilidad de Derecho de Negocios que de Derecho Comercial, tanto las reglas de aquél se extendieron a todas las actividades profesionales (cit., p. 21). Por su parte, HuE escribe que puede considerarse que el Derecho Comercial, en su forma extendida Ilamada Derecho de Negocios, se aplica ahora, salvo excepción, también a las actividades civiles, siempre que tengan una finalidad económica (HuE, Jean-Pierre, Introduction élémentaire au droit, Éditions du Seuil, Paris, 1997, p. 168). RıcCl, a su vez, parece tender a identificar Derecho Comercial y Derecho de Negocios (Rıccl, Jean-Claude, Introduction à l'étude du droit, $2^{\mathrm{a}}$ ed., Hachette, Paris, 2002, p. 36). 


\subsection{La autonomía práctica del Derecho de los Museos}

Hay razones pragmáticas para hacer autónomas las normas que regulan específicamente los museos; lo mismo es decir, que el Derecho de los Museos tiene autonomía práctica.

La razón principal de la autonomía es, a nuestro juicio, la existencia de un marco legislativo disciplinario diferenciado: la mencionada Ley de los Museos, cuyo objeto se limita a la regulación jurídica de los museos (y sin perjuicio de la considerable e importante legislación subsidiariamente aplicable, alguna de la cual expresamente referida en varios puntos de su articulado).

Cabe señalar que se trata de una innovación, como ha sido reconocido expresamente por el Gobierno en su propuesta de ley, al consignar como digno de destacar "el hecho de ser la primera vez que hay legislación dedicada exclusivamente a los museos, aunque todavía con un efecto parcial tanto del punto de vista disciplinario, como patrimonial" ${ }^{\prime \prime 6}$.

Esta autonomía práctica se entiende bien, teniendo en cuenta que los museos son realidades bastante bien delimitadas ( $y$, por tanto, inconfundibles) en el ideario social, lo que conduce a la indiscutible comodidad de tener un cuerpo normativo específicamente acantonado en un instrumento de ley separado. La dimensión de la institucionalidad de los museos basta, estrictamente hablando, para sustentar la autonomía práctica del Derecho de los Museos, dispensando otras consideraciones.

\section{CONCLUSIONES}

Al llegar al final de este pequeño periplo de investigación, creemos que pueden condensarse los resultados de la misma en las siguientes proposiciones nucleares:

1. Desde el punto de vista sustantivo, el conjunto de normas jurídicas que puede designarse como Derecho de los Museos gira en torno a la realidad socio-jurídica "museo", este a su vez inseparable (socialmente, lógicamente y jurídicamente) de la realidad "bienes culturales".

2. La realidad "museo" consustancia una institución, por lo que, considerando una capital división sistemática del Derecho, se deduce que el Derecho de los Museos se inscribe en el Ilamado Derecho Institucional.

3. La realidad identificada como "patrimonio cultural" (conjunto de los bienes culturales) corresponde también a la noción de institución; las normas que rigen

\footnotetext{
${ }^{56}$ Propuesta de Ley Marco de los Museos Portugueses ("Proposta de Lei-Quadro dos Museus Portugueses"), № 1 de la Exposición de Motivos ("Exposição de Motivos"), consultado el 19 de abril de 2011, en <http://www.portugal.gov.pt/pt/GC15/Governo/Ministerios/MC/Documentos/Pages/20040318_ MC_Doc_Lei_Museus.aspx>.
} 
esta realidad, y que pueden llamarse en su conjunto Derecho del Patrimonio Cultural, caben también por lo tanto en el ámbito del Derecho Institucional.

4. En razón de los factores que, en el mundo jurídico, llevan a un cierto grado de individualización, el Derecho de los Museos tiene, bajo el actual ordenamiento jurídico portugués, una innegable autonomía práctica, y hay que reconocerle también una incontestable autonomía didáctica (en el sentido que asignamos a estas expresiones).

5. Pero el Derecho de los Museos carece, en el contexto del actual sistema jurídico portugués, de autonomía científica; esa inexistencia de autonomía científica se identifica con el hecho de que ese conjunto de normas jurídicas no tiene principios generales caracterizadores (además de la ausencia de cualquier otra nota que le daría ese tipo de autonomía).

6. En cuanto al universo jurídico-científico, y sin hablar aquí de la problemática de la propia autonomía científica del Derecho del Patrimonio Cultural, entendemos, por las razones presentadas a lo largo de la exposición, que el Derecho de los Museos es un área o sector de aquel otro campo del Derecho ${ }^{57}$.

7. En realidad, y en términos sustanciales, la institución jurídica "museo" es accesoria de la categoría jurídica de los "bienes culturales", que suministran a aquella su razón de ser y determinan el esquema básico de la misma.

\section{BibliografíA}

Abreu, Regina, "A cultura do mecenato no Brasil: uma utopia possível?", in NASCIMENTO Junior, J. do (org.), Economia de museus, Brasília, Ministério da Cultura-Instituto Brasileiro de Museus, 2010, pp. 163-201.

AÑon, María José, "Las Ramas del Ordenamiento Jurídico", in DE LuCAS, J. (ed.), Introducción a la Teoría del Derecho, $3^{\text {a }}$ ed., Valencia, Tirant Lo Blanch, 1997, pp. 171-193.

ArRieta Urtizberea, Iñaki, "La Nueva Museología, el patrimonio cultural y la participación ciudadana a debate", in ArRieta UrTizbereA, I. (ed.), Participación ciudadana, patrimonio cultural y museos: Entre la teoría y la praxis, Universidad del País Vasco, Bilbao, 2008, pp. 11-22, consultado el 10 de septiembre de 2010, en http://www.argitalpenak.ehu.es/p291-content/es/ contenidos/libro/se_indice_arte/es_arte/adjuntos/particip.pdf.

\footnotetext{
${ }^{57}$ Téngase en cuenta que, en la exposición de motivos de la propuesta de Ley Marco de los Museos, el Gobierno dice expresamente que la propuesta de ley se integra "en el régimen jurídico aprobado por la Ley 107/2001, del 8 de septiembre, que establece las bases de la política y el sistema de protección y valorización del patrimonio cultural, y consustancia, de modo transversal, el desarrollo legislativo de principios estructurales de la política del patrimonio cultural" (Propuesta de Ley Marco de los Museos Portugueses ("Proposta de Lei-Quadro dos Museus Portugueses"), cit., № 9 de la Exposición de Motivos ("Exposição de Motivos").
} 
AUBERT, Jean-Luc, Introduction au droit et thèmes fondamentaux du droit civil, $10^{a}$ ed., Paris, Armand Colin, 2004.

BeIGnIER, Bernard, y BlérY, Corinne, Manuel d'introduction au droit: Première année de licence-Premier semestre, Paris, Presses Universitaires de France, 2004.

BiAnCA, C. Massimo, Diritto civile, Vol. I, La norma giuridica. I soggetti, $2^{\text {a }}$ ed., Milano, Giuffrè, 2002.

CABRILlaC, Rémy, Introduction générale au droit, 5ª ed., Paris, Dalloz, 2003.

Casalta Nabals, José, Introdução ao Direito do Património Cultural, $2^{\text {a }}$ ed., Coimbra, Almedina, 2010.

Delicado, Ana, A Musealização da Ciência em Portugal, tesis doctoral, Lisboa, Fundação Calouste Gulbenkian-Fundação para a Ciência e a Tecnologia, 2009.

D'Oliveira Martins, Afonso, "Constituição, Administração e Democracia", in AAVV, Nos 25 Anos da Constituição da República Portuguesa de 1976: Evolução Constitucional e Perspectivas Futuras, Lisboa, Associação Académica da Faculdade de Direito de Lisboa, 2001, pp. 461-504.

FerRaz Jr., Tercio Sampaio, Introdução ao Estudo do Direito: Técnica, Decisão, Dominação, 2a ed., São Paulo, Atlas, 1994.

Ferreira da Cunha, Paulo, Pensar o Direito, Vol. II, Da Modernidade à Postmodernidade, Coimbra, Almedina, 1991.

, Traité de droit constitutionnel, Paris, Buenos Books International, 2010.

Freitas do Amaral, Diogo, Curso de Direito Administrativo, Vol. I, $3^{\text {a }}$ ed., 2006, $4^{a}$ reimpresión, Coimbra, Almedina, 2010.

Gomes, Nuno Sá, Introdução ao Estudo do Direito, Lisboa, Lex, 2001.

Gómez Martínez, Javier, Dos museologías: Las tradiciones anglosajona y mediterránea: diferencias y contactos, Gijón, Trea, 2006.

Hernández Ramírez, Macarena, y Ruiz Ballesteros, Esteban, "El patrimonio como proceso social. Intervención, desarrollo y consumo del patrimonio minero en Andalucía", in Arrieta UrtizbereA, I. (ed.), Participación ciudadana, patrimonio cultural y museos: Entre la teoría y la praxis, Universidad del País Vasco, Bilbao, 2008, pp. 129-147, consultado el 10 de septiembre de 2010, en http://www.argitalpenak.ehu.es/p291-content/es/contenidos/libro/ se_indice_arte/es_arte/adjuntos/particip.pdf.

HuE, Jean-Pierre, Introduction élémentaire au droit, Paris, Éditions du Seuil, 1997. KeEne, Suzanne, Fragments of the World: Uses of Museum Collections, Oxford, Elsevier Butterworth Heinemann, 2005.

LOPES, João Teixeira, "Notas conclusivas. Os museus como terceiras culturas", in Semedo, A., y Lopes, J. T. (coord.), Museus, discursos e representações, Porto, Afrontamento, 2005, pp. 197-199. 
Mainguy, Daniel, Introduction générale au droit, $3^{\text {a }}$ ed., Paris, Litec, 2002.

Marandino, Martha, Almeida, Adriana Mortara, y Valente, Maria Esther Alvarez, "Introdução", in Marandino, M., Almeida, A. M., y Valente, M. E. A. (org.), Museu: lugar do público, Rio de Janeiro, Fiocruz, 2009, pp. 9-13.

Medeiros, Rui, "A Carta dos Direitos Fundamentais da União Europeia, a Convenção Europeia dos Direitos do Homem e o Estado Português", in AAVV, Nos 25 Anos da Constituição da República Portuguesa de 1976: Evolução Constitucional e Perspectivas Futuras, Lisboa, Associação Académica da Faculdade de Direito de Lisboa, 2001, pp. 225-293.

Polettı, Ronaldo, Introdução ao Direito, $3^{\text {a }}$ ed., São Paulo, Saraiva, 1996.

Rebelo de Sousa, Marcelo, y Matos, André Salgado de, Direito Administrativo Geral, Vol. I, $3^{\text {a }}$ ed., Introdução e Princípios Fundamentais, Alfragide, Dom Quixote, 2008.

Reis Novals, Jorge, Direitos Sociais: Teoria Jurídica dos Direitos Sociais enquanto Direitos Fundamentais, Coimbra, Wolters Kluwer (Coimbra Editora), 2010.

ReHBINDER, Manfred, Einführung in die Rechtswissenschaft: Grundfragen, Grundlagen und Grundgedanken des Rechts, 8 a ed., Berlin-New York, De Gruyter, 1995.

Rıccl, Jean-Claude, Introduction à l'étude du droit, $2^{\mathrm{a}}$ ed., Paris, Hachette, 2002.

Semedo, Alice, "Introdução", in Semedo, A., y Lopes, J. T. (coord.), Museus, discursos e representações, Porto, Afrontamento, 2005, pp. 13-26.

VARrICCHIO, Enzo, "Il Diritto Museale, ontogenesi di una disciplina giuridica", Nuova Museologia, giugno 2008, № 18, pp. 2-7, consultado el 10 de septiembre de 2010, en http://www.nuovamuseologia.org/n18/n18.pdf.

Villarroya Planas, Anna, y Escardíbul Ferrá, Josep-Priol, "Panorámica de la situación museística en España", in NASCIMENTO JUNIOR, J. do (org.), Economia de museus, Brasília, Ministério da Cultura-Instituto Brasileiro de Museus, 2010, pp. 73-98.

YúDICE, George, "Museu molecular e desenvolvimento cultural", in NASCIMENTO JunIOR, J. do (org.), Economia de museus, Brasília, Ministério da CulturaInstituto Brasileiro de Museus, 2010, pp. 21-52. 
